\title{
Saccharomyces cerevisiae transcriptional reprograming due to bacterial contamination during industrial scale bioethanol production
}

\author{
Osmar V Carvalho-Netto ${ }^{1,2}$, Marcelo F Carazzolle' ${ }^{1}$ Luciana S Mofatto ${ }^{1}$, Paulo JPL Teixeira ${ }^{1}$, Melline F Noronha', \\ Luige AL Calderón ${ }^{1}$, Piotr A Mieczkowski ${ }^{3}$, Juan Lucas Argueso ${ }^{2}$ and Gonçalo AG Pereira ${ }^{1 *}$
}

\begin{abstract}
Background: The bioethanol production system used in Brazil is based on the fermentation of sucrose from sugarcane feedstock by highly adapted strains of the yeast Saccharomyces cerevisiae. Bacterial contaminants present in the distillery environment often produce yeast-bacteria cellular co-aggregation particles that resemble yeast-yeast cell adhesion (flocculation). The formation of such particles is undesirable because it slows the fermentation kinetics and reduces the overall bioethanol yield.
\end{abstract}

Results: In this study, we investigated the molecular physiology of one of the main S. cerevisiae strains used in Brazilian bioethanol production, PE-2, under two contrasting conditions: typical fermentation, when most yeast cells are in suspension, and co-aggregated fermentation. The transcriptional profile of PE-2 was assessed by RNA-seq during industrial scale fed-batch fermentation. Comparative analysis between the two conditions revealed transcriptional profiles that were differentiated primarily by a deep gene repression in the co-aggregated samples. The data also indicated that Lactobacillus fermentum was likely the main bacterial species responsible for cellular co-aggregation and for the high levels of organic acids detected in the samples.

Conclusions: Here, we report the high-resolution gene expression profiling of strain PE-2 during industrial-scale fermentations and the transcriptional reprograming observed under co-aggregation conditions. This dataset constitutes an important resource that can provide support for further development of this key yeast biocatalyst.

Keywords: Saccharomyces cerevisiae, Bioethanol, Co-aggregation, Transcriptome, RNA-seq

\section{Background}

Brazilian bioethanol is mainly produced from the fermentation of sugarcane juice and molasses by Saccharomyces cerevisiae. Yeast cells are added at the beginning of the production season and are recycled at the end of each fedbatch fermentation cycle, every 8 to 15 hours, for approximately 210 consecutive days. Because the feedstock is not completely sterilized prior to fermentation, microbial contaminants are continuously introduced to the distillery environment, resulting in a dynamic competition between the desired inoculated strain and wild yeast strains and bacteria [1-3].

\footnotetext{
* Correspondence: goncalo@unicamp.br

${ }^{1}$ Departamento de Genética, Evolução e Bioagentes, Instituto de Biologia, Universidade Estadual de Campinas, Campinas, SP, Brazil

Full list of author information is available at the end of the article
}

PE-2 and CAT-1 are the most versatile and widely adopted S. cerevisiae strains used by Brazilian distilleries [1]. Previously, we described the genome structure of the JAY270 strain, a clonal isolate derived from a commercial PE-2 stock [4]. That study provided initial insights into the genetic mechanisms that underlie the strong performance of this strain as an industrial biocatalyst. JAY270 is a heterothallic diploid strain, and its genome is characterized by a high degree of heterozygosity. This intrinsic genetic diversity is likely a key factor in the extraordinary ability of PE-2 to thrive in the harsh environment found in industrial fermentation tanks. PE-2 typically persists for the whole production season as the dominant strain in the yeast population, stemming the proliferation of wild contaminant yeast strains.

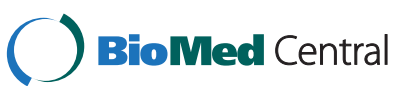

(c) 2015 Carvalho-Netto et al.; licensee BioMed Central. This is an Open Access article distributed under the terms of the Creative Commons Attribution License (http://creativecommons.org/licenses/by/4.0), which permits unrestricted use, distribution, and reproduction in any medium, provided the original work is properly credited. The Creative Commons Public Domain Dedication waiver (http://creativecommons.org/publicdomain/zero/1.0/) applies to the data made available in this article, unless otherwise stated. 
Yeast flocculation is a phenotype derived from cell-cell adhesion controlled by a well-characterized pathway (FLO gene family members, and their transcriptional regulators). This pathway is activated in response to environmental cues including cell density, carbon and/or nitrogen sources, $\mathrm{pH}$, temperature, oxygen, agitation, ethanol concentration, and the presence of cations (reviewed by $[5,6]$ ). Flocculation is undesirable during fed-batch bioethanol production because it impairs the centrifugation step required for cell recycling, and it also reduces the cellsubstrate contact surface, thereby slowing fermentation kinetics and reducing yield $[1,7]$.

Most strains used in sugarcane bioethanol production, including PE-2, are non-flocculant in pure culture. However, industrial-scale fermentations employing these strains occasionally exhibit flocculation-like features that cause significant productivity losses. In those cases, the flocculationlike phenotype is typically due to co-aggregation between yeast and bacterial contaminant cells $[7,8]$, rather than conventional genetically determined yeast self flocculation. Lactobacillus species are the main bacterial contaminants found in sugarcane bioethanol production due to their ability to tolerate ethanol stress $[8-11 \%(\mathrm{v} / \mathrm{v})]$ and the antibacterial acid wash administered to the yeast cells prior to pitching each new batch (pH $2.0-3.0)$ [9]. L. fermentum, $L$. vini and $L$. plantarum, have been reported to be the main agents responsible for the co-aggregation of yeast cells $[10,11]$. The mannose-specific adhesin (Msa) found in L. plantarum and L. fermentum has been implicated in cell-cell interactions [12-14]. Hirayama et al. [15] examined co-aggregation in a panel of $S$. cerevisiae mutants with gene deletions of twelve mannan cell wall constituents. Among them, the mnn2 $2 \Delta$ mutant strain lost the capacity to co-aggregate with $L$. plantarum cells. Mnn2p is a mannosyltransferase that transfers the first $\alpha$-1,2-linked mannose to the mannan core structure to form a side chain that is subsequently extended by Mnn5p [16]. In the absence of Mnn2p, the mutant identified by Hirayama et al. [15] has an unbranched mannan chain that is incapable of linkage to the bacterial adhesin Msa.

Although S. cerevisiae is an acid-tolerant organism [17], exposure to high concentrations of organic acids produced by bacterial contaminants slows down the yeast metabolism and reduces fermentative fitness [18-20]. Narendranath et al. [21] reported that the synergism between lactic and acetic acids reduced the rates of yeast growth, glucose consumption, and ethanol production.

Although recent advances have been made in the characterization of the cellular pathways that contribute to the success of PE-2 as a bioethanol producer, such laboratory-based studies cannot accurately replicate the biotic and abiotic stresses encountered by this strain during industrial-scale fermentations [7,22]. To gain a better understanding of the molecular physiology of
PE-2 under actual production conditions, we determined the gene expression profiles from cells collected directly from distilleries, and contrasted them to the transcriptional responses triggered by co-aggregation with bacterial contaminants. This dataset provides valuable information to support the genetic improvement of PE-2 and other bioethanol-producing strains, specifically, in the development of strategies to reduce or avoid co-aggregation in the presence of bacterial contaminants.

\section{Results and discussion}

\section{Experimental dataset}

Brazilian sugarcane bioethanol fermentation is characterized by a dynamic competition between high productivity industrial yeast strains and wild yeast and bacteria that contaminate the production process [1-3]. Early in the 2009 sugarcane harvest season (April), a pronounced flocculation-like phenotype was observed in the yeast population at a distillery in São Paulo state. Since the PE-2 yeast strain used as the initial inoculum is nonflocculant, the cell-cell adhesion observed was likely caused by co-aggregation between yeast cells and bacterial contaminants [7]. On that occasion, we collected samples directly from the fermentation tanks at seven time points of a single fed-batch cycle from this flocculated (FL) condition. The distillery's operator initiated a combination of antibiotic and acid treatments to control the bacterial contamination and cellular co-aggregation. This treatment lasted for several weeks and was effective. By July, the culture had fully reverted to its original non-flocculated state (typical fermentation; TF), despite present similar number of bacteria $\left(1 \times 10^{6} \mathrm{CFU} / \mathrm{mL}\right)$. We then returned to the distillery and collected samples at six time points from the beginning to the end of a single disaggregated fed-batch cycle.

We isolated random yeast colonies from the FL and TF samples and genotyped them using PE-2 specific PCR markers recently developed by our group [2]. Despite the three-month interval between the collections, $95 \%$ of the yeast colony isolates from either flocculation condition matched the unique banding profile of the original PE-2 inoculum (data not shown). This result was consistent with the high degree of adaptation and persistence in long-term fed-batch sugarcane fermentation with cell recycling that is the hallmark feature of the PE2 strain. It also reassured us that PE- 2 was indeed the major yeast strain present in the microbial population, therefore allowing us to interpret the results of the transcriptomics studies presented below as a reflection of the molecular physiology of this particular strain.

\section{Alignment of RNA-seq reads and microbial identification}

The RNA-seq libraries from the six TF and seven FL samples were sequenced using Illumina technology 
(see Methods). Combined, they totaled approximately 330 million 36-bp single-end reads and approximately $11.9 \mathrm{~Gb}$ of sequence information. On average, approximately $76 \%$ of the reads from each sample aligned to reference $S$. cerevisiae genes and were interpreted as being derived from PE-2 transcripts (Methods and Additional file 1).

The material used to prepare the sequencing libraries also included some non-mRNA molecules, which were also sequenced and generated reads. We took advantage of this feature of the data and mined it for sequences derived from the bacterial cells present in the fermentations. We performed rRNA identification through alignment of the RNA-Seq reads to the SILVA rRNA database [23]. An average of approximately $5 \%$ of the total reads were classified as ribosomal sequences, with $0.26 \%$ being assigned to a bacterial origin (Additional file 1). The bacterial read counts per taxon were calculated for the different taxonomic levels using the SILVA rRNA database. The family level distribution of the bacterial sequences detected in the two fermentation conditions sampled are shown in Figure 1A. Interestingly, TF and FL had a similar overall distribution of bacterial families. However, within the Lactobacillaceae family, most of the reads derived from the flocculated condition were assigned to a single species, Lactobacillus fermentum ( 93\%) (Figure 1B). In contrast, only $41 \%$ of the Lactobacillaceae reads belonged to this species in the typical fermentations. This observation was significant since $L$. fermentum has been reported to induce sedimentation in $S$. cerevisiae $[9,10]$. To evaluate in principle the ability of L. fermentum to induce co-agregation with PE-2, we isolated bacterial colonies from this species from our FL samples and confirmed their identity by $16 \mathrm{~S}$ rDNA PCR and Sanger sequencing. These isolates were co-cultured with PE-2 under laboratory conditions and a comparable behavior to that observed at the distillery was observed (Figure 1C and $\mathrm{D})$. The PE-2 yeast cells became co-aggregated and sedimented when co-cultured with greater than $1 \times 10^{5}$ L. fermentum cells $/ \mathrm{mL}$. A representative scanning electron micrograph of PE-2 yeast and L. fermentum bacterial cells from these co-cultures under laboratory conditions is shown in Figure 1E.

\section{Metabolite analysis}

Analysis of the chemical composition of the collected samples revealed four significant differences in the kinetics of flocculated versus typical fermentation (Figure 2). Compared to the TF samples, the FL samples had (i) lower final ethanol titer, (ii) lower glycerol production, (iii) higher lactic and acetic acid concentrations, and (iv) slower rate of sucrose hydrolysis.

The fermentation batches took longer to complete in FL (21 hours) than in TF (15 hours), and the final ethanol content of the FL samples $(64.4 \mathrm{~g} / \mathrm{L})$ was $~ 25 \%$ lower than that of the TF samples, although both had somewhat similar residual sugar levels (FL: $7.6 \mathrm{~g} / \mathrm{L}$; TF: $4.5 \mathrm{~g} / \mathrm{L}$ ).

Glycerol production by yeast cells is inversely associated with ethanol titer [1]; however, the production of a limited amount of glycerol is important to help maintain

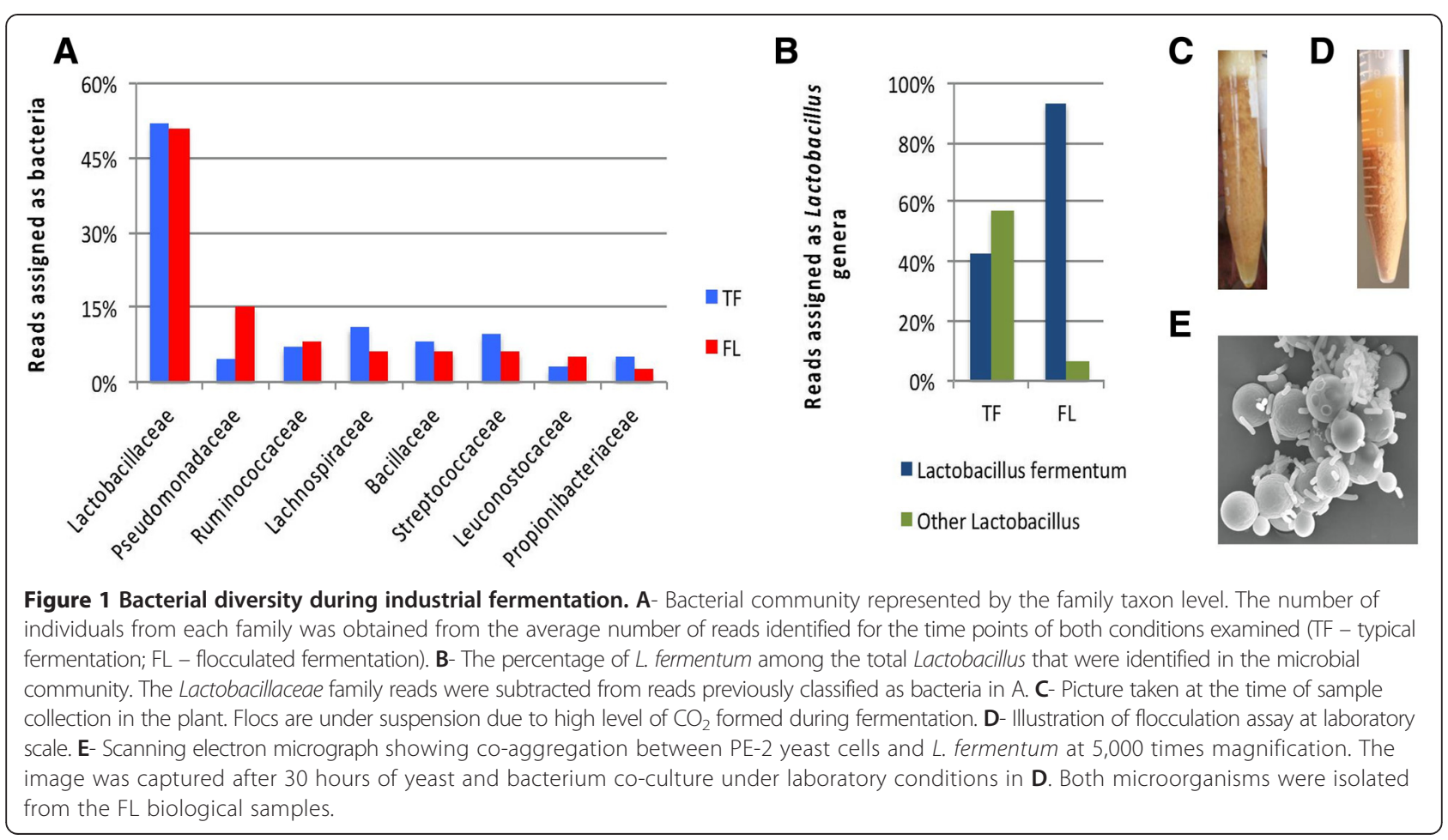



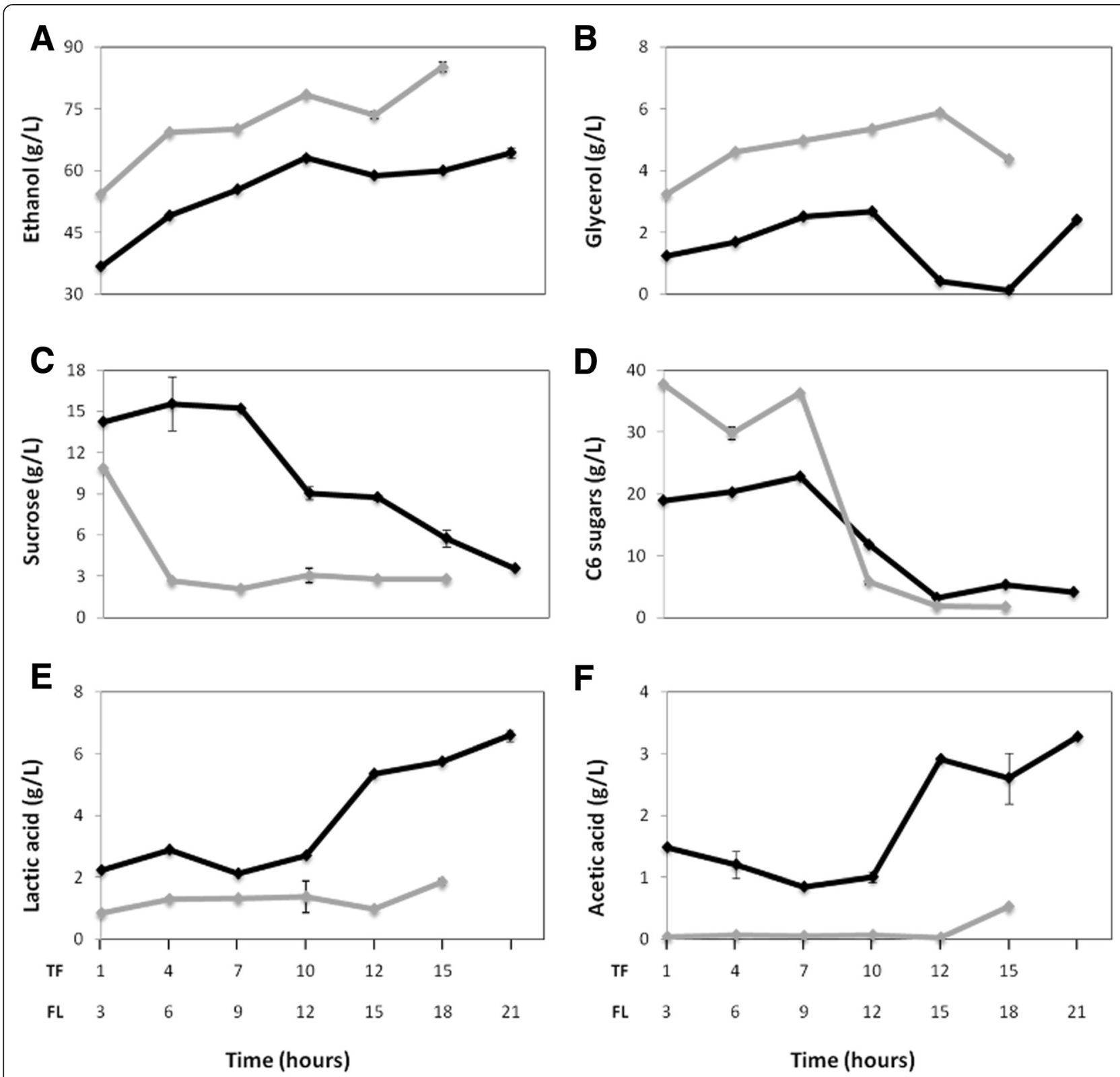

Figure 2 Kinetics of production and consumption of major compounds examined during the fermentations. Content in g/L of: A- ethanol; B- glycerol; C- sucrose; D- C6 sugars (glucose and fructose); E- lactic acid; and F- acetic acid. The compounds were measured with HPLC equipment using samples collected during the fermentations. FL - flocculated fermentation: black lines; TF - typical fermentation: gray lines. Standard deviation bars were obtained using three technical replicates for each time point. Please, note that the same time points between the two fermentation conditions (eg. FL3 vs. TF3) are not directly comparable in isolation, as they do not necessarily correspond to the same stage along each fermentation.

an optimal redox equilibrium and proper cellular osmoregulation $[24,25]$. One of the many desirable properties of PE-2 is its well-balanced production of glycerol, which is low enough to have high ethanol yield, but high enough to tolerate stress. Interestingly, TF samples had almost three times higher glycerol concentration $(4.74 \mathrm{~g} / \mathrm{L})$ than FL, suggesting that the FL cells were metabolically imbalanced and thus were likely less tolerant to the stressful environment of industrial fermentation.
Saccharomyces cerevisiae strains do not produce high amounts of organic acids $[17,26]$, therefore most organic acids detected during bioethanol production have been attributed to bacterial contaminants, primarily Lactobacillus $[9,27]$. Under laboratory conditions, PE-2 produces only 1.5 and $2.4 \mathrm{mg} / \mathrm{L}$ of lactic and acetic acids, respectively [18]. In our study, the final content of acetic and lactic acids was 6 and 3.5 fold higher, respectively, in FL relative to TF (Figure 2). Since the overall residual sugar contents 
were similar at the end of both fermentation conditions, the flow of the sugar feedstock must have been significantly altered in the FL fermentation condition, being diverted from the intended ethanol production by yeast to instead being misused by bacterial contaminants to produce organic acids.

Due to its prolonged duration and the low ethanol titer, we estimated that co-aggregated fermentation resulted in the loss of approximately 12 million liters of bioethanol during the three months that the distillery operated under this condition, underscoring the critical importance of this problem to the bioethanol industry.

\section{Differential gene expression analysis}

The number of reads from the respective RNA-seq libraries that aligned to reference genes was used in the identification of differentially expressed (DE) genes between the time courses of the two fermentation conditions, as well as within each of the two conditions (Table 1). Time points TF1 and FL1 were used as references. Gene expression comparisons between fermentations (Table 1, C-Comparative) were performed by comparing time points from early phases of fermentation (e.g. TF1 vs. FL1) and late stages (e.g. TF6 vs. FL7). Moreover, we performed a global analysis using all TF libraries versus all FL libraries (TFs vs. FLs) to examine the cumulative effect of all time points for each fermentation

Table 1 Differentially expressed genes during industrial bioethanol fermentation under two distinct conditions

\begin{tabular}{llll}
\hline $\begin{array}{l}\text { A- Typical } \\
\text { fermentation }\end{array}$ & DE genes & $\begin{array}{l}\text { Down-regulated } \\
\text { genes }\end{array}$ & $\begin{array}{l}\text { Up-regulated } \\
\text { genes }\end{array}$ \\
\hline TF1 vs. TF2 & 305 & 165 & 140 \\
TF1 vs. TF3 & 989 & 577 & 412 \\
TF1 vs. TF4 & 1506 & 554 & 952 \\
TF1 vs. TF5 & 1609 & 581 & 1028 \\
TF1 vs. TF6 & 2396 & 1588 & 808 \\
B- Flocculated & & & \\
fermentation & & 261 & 92 \\
FL1 vs. FL2 & 353 & 518 & 161 \\
FL1 vs. FL3 & 679 & 1278 & 569 \\
FL1 vs. FL4 & 1847 & 2882 & 530 \\
FL1 vs. FL5 & 3412 & 3034 & 484 \\
FL1 vs. FL6 & 3518 & 3263 & 472 \\
FL1 vs. FL7 & 3735 & & 508 \\
C- Comparative & & 95 & 218 \\
TF1 vs. FL1 & 603 & 1255 & 116 \\
TF6 vs. FL7 & 1473 & 274 & \\
TFs vs. FLs & 390 & &
\end{tabular}

Genes were considered differentially expressed (DE) if they had an expression ratio $\geq 2$ or $\leq-2$ and a $p<0.01$. Down-regulated genes included TF1 (A), FL1 (B) and TF1, TF6 and TFs (C). Up-regulated genes included TF2-TF6 (A), FL2-FL7 (B) and FL1, FL7 and FLs (C). condition. DE genes were obtained from the global analysis using gene expression averages from the six timepoints of TF compared with the seven time-points of FL, with a p-value cutoff of 0.01 (Table 1). The complete RNA-seq data are available at the Gene Expression Omnibus (http://www.ncbi.nlm.nih.gov/geo) under accession number [GSE41834] (Additional file 1), and the lists of DE genes are shown in Additional files 2, 3 and 4.

Despite the lower content of ethanol obtained in the two conditions, glycolysis-related genes were not differentially expressed between them. Curiously, the sucrosehydrolyzing gene, SUC2, was up-regulated by a factor of 4 in the TF condition. Furthermore, the expression of SUC2 in the TF condition increased three-fold when the addition of sugarcane extract stopped (TF3) and the level of C6 sugars (glucose and fructose) was reduced from $36 \mathrm{~g} / \mathrm{L}$ to $6 \mathrm{~g} / \mathrm{L}$. Figure 3 shows the transcriptional profile of $S U C 2$, described by the RPKM metric and sucrose concentration, as a function of fermentation time for the FL (3B) and TF (3C) conditions. This rapid activation of SUC2 expression appears to be important for the prompt stress response to nutrient limitation (i.e. C6 sugars) during fermentation [28]. However, SUC2 expression in the FL samples decreased seven-fold during the process. This pattern could be partially explained by the presence of sucrose in the FL samples during the entire fermentation process (Figure 2C), which would have provided a continuous supply of C6 sugars to the cells and might have thus caused SUC2 repression [29]. The reduced surface contact between yeast cells and the medium due to cell-cell adhesion in FL could be associated with this distinct pattern of sucrose consumption. Therefore, we can reason that one of the causes of the longer time required for the FL fermentation could be the down-regulation of $S U C 2$, leading to a low availability of fermentable sugars.

Although S. cerevisiae is a vigorous and acid-tolerant fermentative organism [17], high concentrations of organic acids with a low $\mathrm{pH}$ and high concentration of ethanol reduce its metabolic rate [18-20]. We determined the $\mathrm{pH}$ for the FL and TF samples and obtained comparable measurements ranging from $\mathrm{pH} 3.8$ to $\mathrm{pH}$ 4.3. As shown in Figure 3D, the overall levels of gene expression decreased when the organic acid content reached values greater than $4 \mathrm{~g} / \mathrm{L}$ in the $\mathrm{FL}$ samples, suggesting that organic acids produce strong gene repression in the yeast cells. In this case, fewer genes were expressed and at lower levels compared with the previous time-points. At the low $\mathrm{pH}$ of fermentative conditions, the organic acids produced by contaminating bacteria exist primarily in their undissociated state [30]. Such undissociated organic acids present in the substrate diffuse across the cell membrane and dissociate in the cytoplasm, generating protons that lower the intracellular $\mathrm{pH}$ and inhibit many metabolic functions 


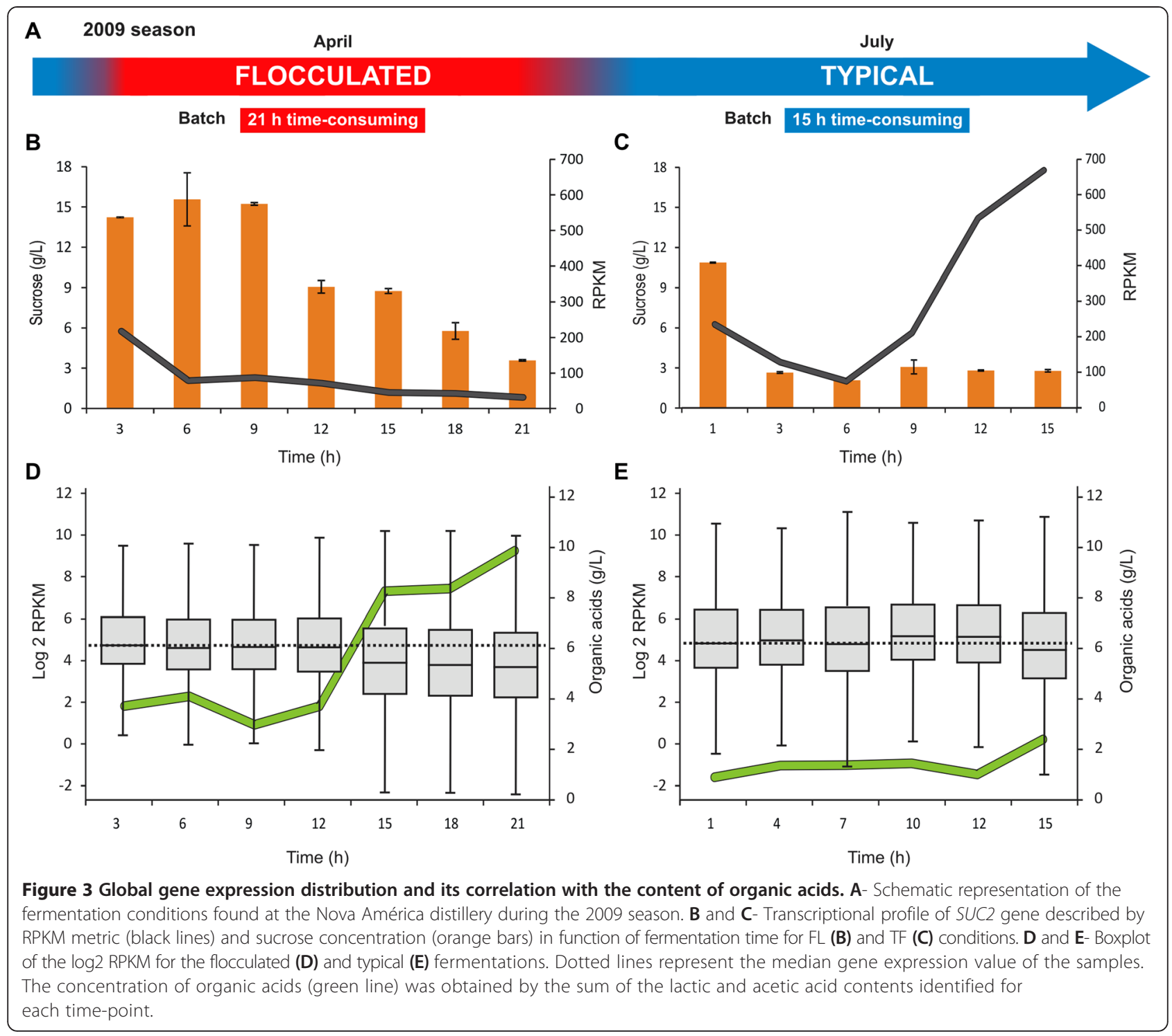

[31]. Moreover, this dissociation produces charged anions that can in turn produce free radicals, leading to severe oxidative stress [31]. Narendranath et al. [21] reported a negative synergist effect between lactic and acetic acids when concentrations of organic acids are present in the medium at $0.5 \%(\mathrm{w} / \mathrm{v})$ and $0.04 \%(\mathrm{w} / \mathrm{v})$, respectively. This combination inhibited the cellular growth rate and decreased the rates of glucose consumption and ethanol production.

Genes related to flocculation (MUC1, FLO5, FLO8, FLO9, FLO1O and PHD1) were not found to be upregulated in the FL samples (Figure $4 \mathrm{~A}$ ). This result confirmed that the observed cellular co-aggregation was not due to yeast genetic control. We observed that the main transcriptional differences between the FL and TF conditions were related to content variations in the concentrations of organic acids present in the medium. The major plasma membrane $\mathrm{H}^{+}$-ATPase, encoded by PMA1 [32], was not differentially expressed between samples at the beginning of fermentation (TF1 vs. FL1). However, we verified a two-fold PMA1 induction in flocculated fermentations at the last time point. Pmalp-related genes, AST1 (targeting factor to plasma membrane), PMP1, PMP2 and HRK1 (regulatory elements), had similar expression patterns (Figure 4B). These data show that the mechanism used to pump out protons to regulate cytoplasmic $\mathrm{pH}$ is up-regulated in the FL cells. This stress response, however, consumes excessive ATP and may cause an inhibitory action by energy depletion [31].

Previous studies have shown that the main transcriptional responses of $S$. cerevisiae in the presence of weak acids (lactic and acetic) are related to cell wall components, membrane-associated transport processes and iron homeostasis [19,33,34]. The HAA1 transcription 


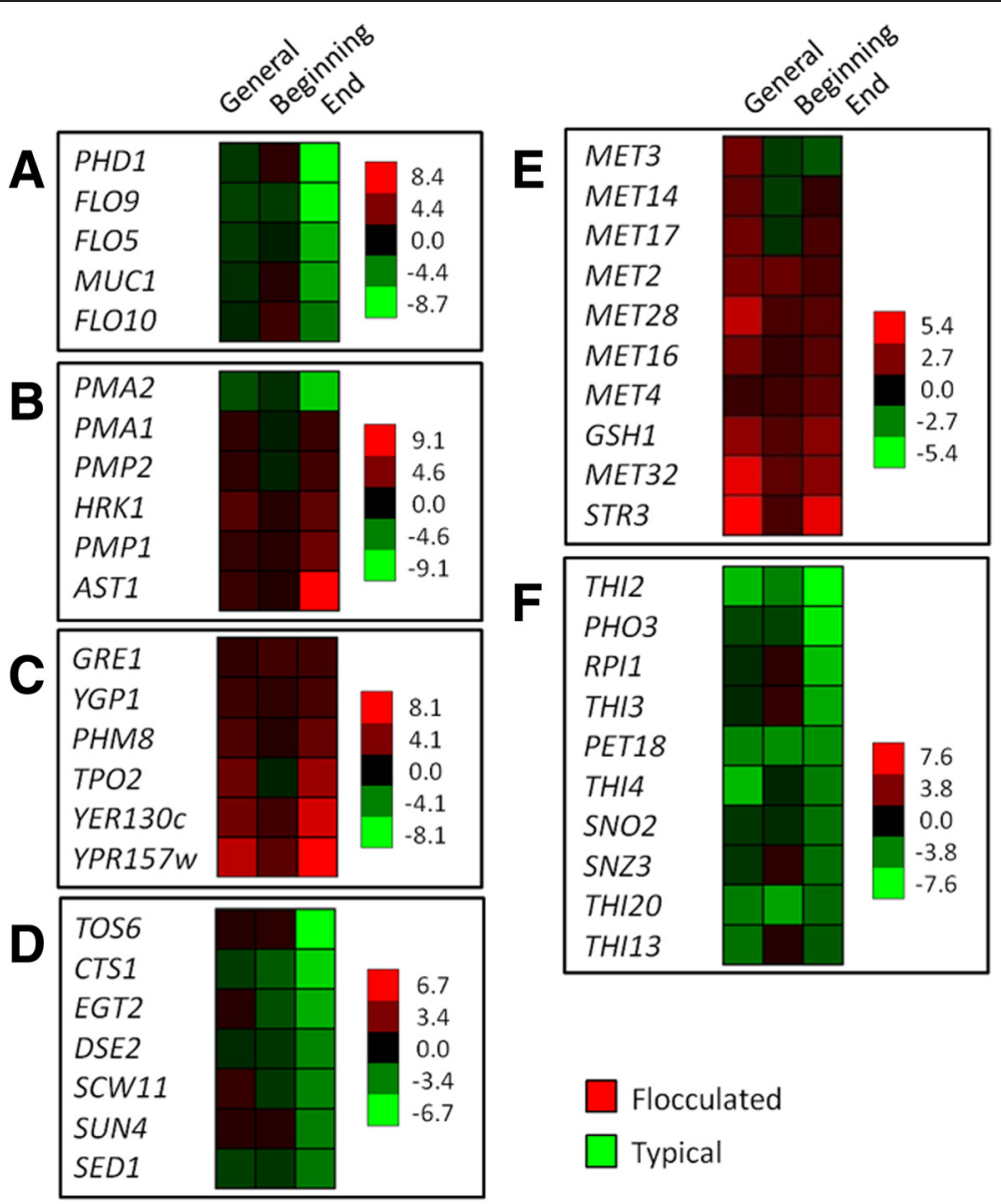

Figure 4 Gene expression comparisons between typical and flocculated fermentations. A- FLO genes and flocculation activators; B- Plasma membrane $\mathrm{H}^{+}$-ATPase (PMA1) and related genes; C- Haa1p target genes; D- Cell wall components; E- Methionine- and glutathione-related genes; F- Thiamine metabolic process genes. Differentially expressed (DE) genes were defined as those with a fold change $\geq 2$ or $\geq-2$ and a $p$-value $<0.01$. Negative values were obtained for the TF samples, and positive values were obtained for the FL samples. General analysis (TFs vs. FLs) was performed using six time-points for the TF samples and seven time-points for the FL samples. The beginning of fermentation is denoted as TF1 and FL1, and the end of fermentation is denoted as TF6 and FL7. The software Expander6 was used for the gene clustering image drawn using the end of fermentation as a reference.

factor and Haalp-regulated genes have been reported to be up-regulated in response to lactic and acetic acids [34-37]. Among the Haalp target genes, we observed the up-regulation of TPO2, YGP1, PHM8, GRE1, YPR157w, YER130c and HRK1 in the FL7 sample compared with TF6 (Figure $4 \mathrm{C}$ ). However, we did not observe differences in the expression of HAA1 itself between fermentations, suggesting a co-regulation of those seven genes by distinct transcription factors [36].

During FL, cell wall-related genes changed their expression dramatically compared with TF. Kawahata et al. [19] reported that the depleted expression of the cell wall components SED1, DSE2, CTS1, EGT2, SCW11, SUN4 and TOS6 increased the resistance of S. cerevisiae to lactic acid. Here, the PE-2 strain used the same mechanism for FL, down-regulating these seven genes by a factor of 3- to 6.8-fold in response to the organic acid concentrations at the end of the FL time course (Figure 4D).

To validate the RNA-seq data, 15 genes were assessed by RT-qPCR, for a total of 60 pairwise comparisons. The total expression trends of the time-points analyzed were $87 \%$ similar between the different techniques, with correlation values of $R^{2}=0.7604$ and $R^{2}=0.7951$ for the $F L$ and TF samples, respectively (Additional file 5).

\section{Gene ontology of DE genes}

Gene ontology (GO) analyses were performed to identify functional signatures in gene expression using the DE genes between fermentation conditions (TF1 vs. FL1; TF6 vs. FL7; TFs vs. FLs). Two enriched GO terms were particularly meaningful in the context of industrial fermentations: cellular amino acid and vitamin metabolic processes (Additional file 6). 
For the FL samples, several genes assigned as "cellular amino acid metabolic process" (MET2, MET3, MET4, MET14, MET16, MET17, MET28, MET32, STR3 and GSH1) are involved mainly in the methionine (MET) and glutathione (GSH) biosynthesis pathways (Figure 4E). GSH has an important role in the protection of S. cerevisiae against oxidative stress [38,39]. The first, and ratelimiting, step in the GSH biosynthetic pathway occurs when GSH1 catalyzes the conjugation of glutamate and cysteine (reviewed in [40]). Because methionine is involved in cysteine biosynthesis, the expression profile of the MET genes has a direct effect on GSH biosynthesis by supplying cysteine to the pathway [41]. Moreover, the transcription factors for Met4p and Met32p, which are required expression of $M E T$ biosynthetic genes, are also essential for GSH1 expression by cadmium-mediated regulation [42]. The MET- and GSH-related gene expression profiles (up-regulated at FL) suggest that the yeast cells in the FL samples were under oxidative stress, most likely due to the formation of intracellular reactive oxygen species triggered by lactic [43] and acetic [44] acids.

Genes involved in the vitamin-related metabolic process were identified prominently up-regulated in the TF samples. Interestingly, most of the genes identified (e.g., PET18, PHO3, RPI1, THI2, THI3, THI4, THI13, THI20, SNO2 and SNZ3) participate in thiamine (vitamin B1) metabolic processes (Figure 4F). The SNO/SNZ genes are required for vitamin $\mathrm{B} 1$ and $\mathrm{B} 6$ biosynthesis and also have a role in oxidative stress tolerance [45-47]. Moreover, under laboratory conditions, bioethanol strains carrying amplifications of these genes have been shown to be less sensitive to fluctuation in the vitamin B levels when cultured in a medium with a high sugar concentration [48], and these genes have been suggested to be important for adaptive growth in an industrial process $[4,48]$. Our transcriptional data is consistent with those reports and underscores the importance of thiamine genes for the adaptation of the PE-2 strain to sugarcane bioethanol production.

\section{Differential allelic expression}

Sequencing analysis of the PE-2 genome revealed that this strain is highly heterozygous [4]. We took advantage of the high number of PE-2 sequences generated by the RNA-seq reads $(\sim 9 \mathrm{~Gb})$ to identify differences in allelic expression during the different fermentations. Differential allelic expression (DAE) at a threshold of 2-fold between alleles was used for a case of DAE to be called (i.e., more than $66 \%$ of the reads aligned to a specific gene came from a single allele). When the coding region had more than one heterozygous SNP, DAE was determined accounting for the cumulative imbalance for all the phased SNPs across the entire gene.
Our initial analysis identified 195 candidate DAE genes that were found in both TF and FL conditions (Additional file 7; TF and FL). Interestingly, 140 of those genes were located at consecutive positions on the right arm of Chr13, between FAR8 (YMR029c) and the right telomere (TEL13R), and all of them had reads that were essentially derived from only one allele (Figure 5A). This striking pattern suggested that a Chr13 region of approximately $600 \mathrm{~kb}$ was homozygous in the PE- 2 strain present at the time in the distillery, likely due to a mitotic recombination event leading to loss of heterozygosity (LOH). To confirm this homozygous pattern in the industrial isolates, we designed primers to partially amplify the RCE1 (YMR274c) locus, which contains a heterozygous SNP $(\mathrm{A} / \mathrm{G})$ in the JAY270/PE-2 strain at position 874 within a recognition site for the $M b o \mathrm{I}$ restriction endonuclease. RCE1 sequences were amplified from PE-2 cells isolated from the industrial fermentations as well as from the JAY270/PE-2 heterozygous diploid and from the S288c isogenic strain FY23 (uncut allele). The $M b o I$ digestions of the PCR products confirmed that the PE-2 cells isolated from industrial tanks were indeed homozygous for $R C E 1$, while a heterozygous pattern was observed for JAY270 (Figure 5B).

Exclusion of the Chr13 right arm genes resulted in 55 genes with DAE identified in both fermentations. In addition, we also found $61 \mathrm{DAE}$ genes exclusively in the TF samples, and 33 exclusively in the FL samples (Figure 5C and Additional file 7), suggesting a fermentation conditiondependent expression pattern regulated by specific transcriptional responses. We hypothesize that the observed DAE patterns may be due to the differential effect on allele expression of heterozygous SNPs at cis-elements at the regulatory regions of the DAE genes. Gene ontology analysis of the DAE genes did not reveal a functional enrichment in this relatively limited gene set (the only statistically enriched GO term detected was "unknown function"). Although individual cases of DAE may play an important role in dictating the fermentation performance of PE-2 under typical and/or co-aggregated conditions, it is unclear at this point which are those genes and what is their specific function.

\section{Conclusion}

The gap in the basic biological knowledge about PE-2 and its related strains represents a significant barrier to genetically improving these strains and fully exploiting their biotechnological potential [8]. The genetic engineering of bioethanol strains should be preceded by genomic and transcriptomic studies to identify the genetic characteristics that are associated with yeast fermentative fitness $[7,22]$. The results presented here provide new insights into the biology of the PE-2 strain and allowed us to identify stress response mechanisms 

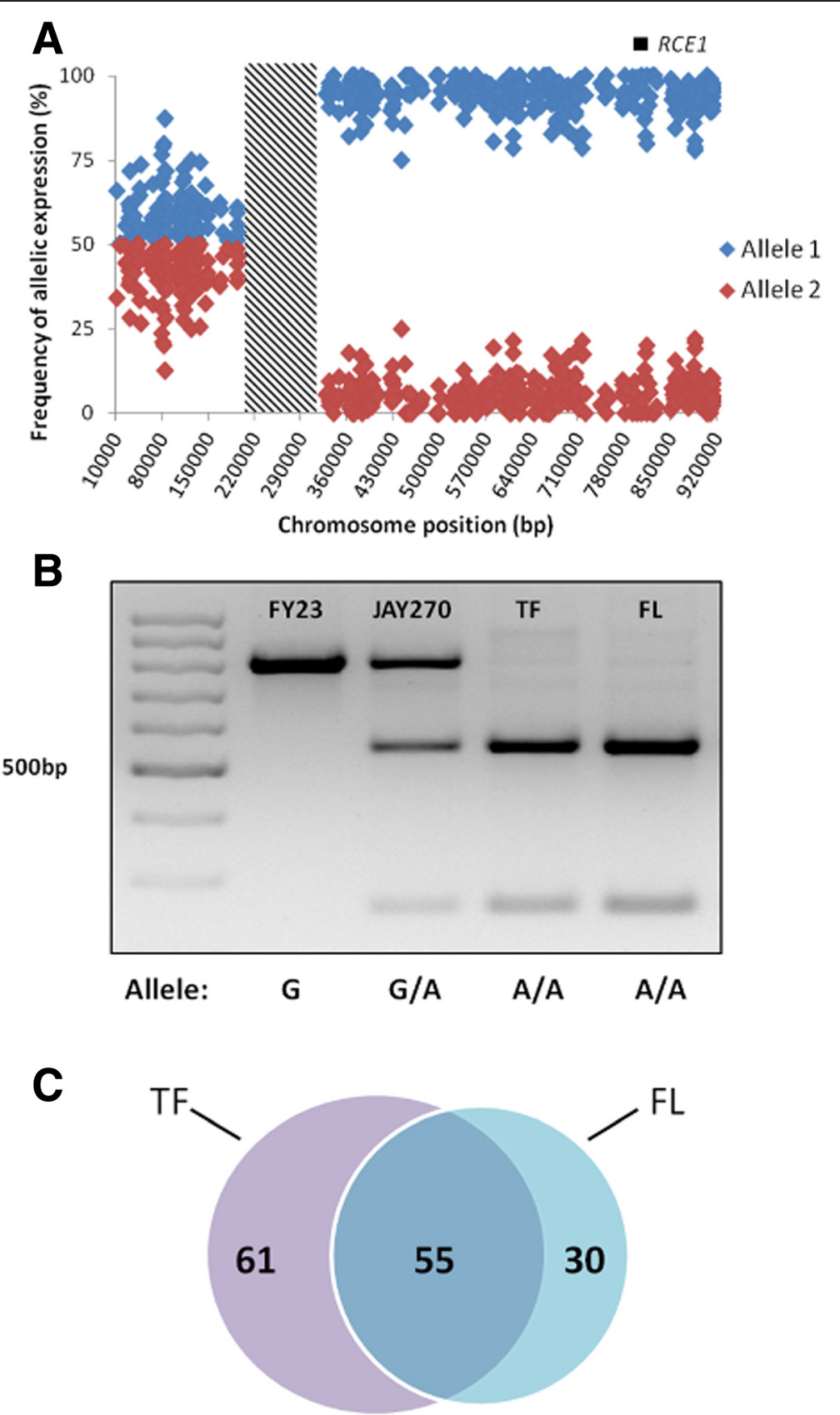

Figure 5 Analysis of differential allelic expression (DAE). A- Allelic expression frequency of the genes located on chromosome 13 (Chr13). The allele with higher expression was arbitrarily designated as allele 1 (blue) and the lower expression allele was designated as allele 2 (red). The hatched box represents a 100-kb homozygous region (including the centromere) in the JAY270/PE2 diploid where no DAE information could be assessed. The DAE plot suggests that the breakpoint of the Chr13 LOH event occurred within the homozygous region. The position of the RCE1 locus on the right arm is shown. B- The genotypes at the RCE1 locus were determined by PCR followed by restriction analysis using Mbol. The predicted banding patterns for the alleles were: Homozygous for allele 1 (cut) 543 bp and 256 bp; Homozygous for allele 2 (uncut) 799 bp; Heterozygous pattern: $799 \mathrm{bp}, 543 \mathrm{bp}$ and $256 \mathrm{bp}$. A molecular weight marker ladder of $100 \mathrm{bp}$ incremental size fragments was used in line 1. The $500 \mathrm{bp}$ marker band is indicated. C- Venn diagram showing the number of DAE genes identified exclusively in the TF and FL, and the DAE genes identified in simultaneously in both TF and FL.

during bioethanol production. Information derived directly from industrial scale fermentations can be used to support studies aimed at developing superior fermentative fitness in the PE-2 strain. The data described here represent an important step to reach those goals. 


\section{Methods}

\section{Fermentation samples collection}

Biological samples from two different industrial fermentation conditions were collected directly from bioethanol fermentation tanks at the Nova América distillery (Maracaí-SP, Brazil). At the beginning of the 2009 season, the PE-2 culture used as the starting inoculum at this distillery became flocculent due to bacterial coaggregation. On that occasion, we collected samples at seven different fermentation time points (FL samples) during one fed-batch cycle. Over the following three months, the yeast cells were treated with antibiotics and sulfuric acid before re-pitching the next batch. The yeast community eventually reverted to its typical phenotype (disaggregated), at which time samples were collected at six intervals during a typical fed-batch fermentation cycle (TF samples). Three biological replicates were collected for each of the thirteen sampled time-points. After collection, the samples were immediately transferred to a container with dry ice for the posterior chemical and transcriptomic analysis. Aliquots of each sample were also maintained on ice to preserve the viability of cells.

\section{Yeast genotyping}

Unfrozen aliquots from each condition (FL and TF) were diluted and plated in YPD solid medium (yeast extract $10 \mathrm{~g} / \mathrm{L}[\mathrm{w} / \mathrm{v}$ ], peptone $20 \mathrm{~g} / \mathrm{L}$ [w/v], glucose $20 \mathrm{~g} / \mathrm{L}$ $[\mathrm{w} / \mathrm{v}]$ and agar $20 \mathrm{~g} / \mathrm{L}[\mathrm{w} / \mathrm{v}])$. Colonies were isolated and DNA extraction was performed following to a phenolchloroform protocol [49]. Twenty yeast colonies derived from each condition were analyzed using PE-2 specific PCR markers as described by Carvalho-Netto et al. [2].

\section{Metabolite analysis}

Aliquots of the biological replicates were centrifuged, and the supernatants were diluted in water (1:3), filtered in Millipore $0.22-\mu \mathrm{m}$ filters, and analyzed by High Performance Liquid Chromatography (Alliance 2795, Waters, Milford, MA, USA) using a refractive index detector (HPLC-RI) and an Aminex HP-87H column (Bio-Rad Laboratories, Hercules, CA, USA). The HPLC readings for sucrose, glucose, fructose, ethanol, glycerol, acetic acid and lactic acid in the samples were fit to respective standard curves to determine their concentrations.

\section{RNA isolation and RNA-seq library preparation}

The total RNA of the samples was extracted using a phenol and chloroform protocol [50]. Illumina RNA-seq libraries were prepared following the manufacturer's recommendations. Briefly, mRNA was isolated from $1 \mu \mathrm{g}$ of the total RNA using oligo(dt) magnetic beads, and then fragmented in the presence of divalent zinc ions. The fragmented RNA was then used for first and second strand cDNA synthesis. Double-stranded cDNA was end-repaired and 3' adenylated for the ligation of sequencing adapters. After adapter ligation, fragments of approximately $250 \mathrm{bp}$ were isolated by gel electrophoresis and PCR amplified. The libraries were validated on an Experion DNA chip (Bio-Rad, Hercules, CA, USA) and quantified using a Qubit fluorometer (Invitrogen, Carlsbad, CA, USA). Each library was sequenced in one lane of an Illumina Genome Analyzer IIx (GAIIx) sequencer, resulting in 20-30 million 36-bp single-end reads.

\section{Gene expression analysis and functional annotations}

The complete dataset of RNA-seq reads has been deposited in SRA under accession number [SRA057038]. For each RNA-seq library, reads were aligned to a custom reference gene database constituted by $S$. cerevisiae S288c genes (www.yeastgenome.org) and 20 JAY291specific genes [4] (Additional file 1). The alignment was performed using SOAPaligner version 2.20 [51], allowing up to two base mismatches and discarding repeat reads. A Perl script was then created to calculate the number of reads aligned per gene for each RNA-seq library.

The output file was analyzed using the DEGseq package [52] for the identification of differentially expressed (DE) genes. Pairwise comparisons within a fermentation condition (typical and flocculated, individually) and between fermentation conditions (typical versus flocculated) are shown in Table 1. For the comparative analysis (TFs vs. FLs), the DEGseq was configured to use the time points within fermentation (TF1-TF6 and FL1-FL7) as experimental replicates. A p-value cutoff of 0.01 , with a fold change $>2$ (up-regulated) or $<-2$ (down-regulated), were used to determine the $\mathrm{DE}$ genes in these comparisons. Gene expression levels were defined using the RPKM formula [53]. Clustering and visualization of the DE genes were obtained using EXPANDER [54].

We also quantified the genomic background transcription (RPKM threshold) using 1787 intergenic regions larger than $500 \mathrm{bp}$. The RPKM threshold was estimated through the alignment of reads to intergenic regions using SOAPaligner [51], allowing up to two base mismatches and discarding all repeat reads. The distribution of the RPKM values from the genes and intergenic regions for each RNA-seq library was used to estimate the RPKM threshold by visual inspection. The gene expression levels with RPKM values below the RPKM threshold were not considered to be expressed genes, and these genes were discarded from the differential expression analysis when the expression levels were below the RPKM threshold in the respective libraries.

Gene ontology (GO) terms of the DE genes were obtained from SGD (http://www.yeastgenome.org/cgi-bin/ GO/goSlimMapper.pl) using the Yeast GO-Slim Process parameters and a cutoff p-value $<0.01$. Functional GO 
enrichment terms were obtained using DE genes between fermentations (TF1 vs. FL1; TF6 vs. FL7; TFs vs. FLs).

\section{RNA-seq validation by Real Time qPCR (RT-qPCR)}

To confirm the RNA-seq results, 15 genes were analyzed by RT-qPCR in four pairwise comparisons (TF1 vs. TF4, TF1 vs. TF6, FL1 vs. FL4 and FL1 vs. FL7), for a total of 60 pairwise comparisons. A list of the genes and primers used is presented in Additional file 8. Aliquots of the samples used to construct the RNA-seq libraries were used in transcriptase reverse reactions to synthesize cDNA using the SuperScript Direct cDNA Labeling System (Invitrogen, Carlsbad, CA, USA) according to the procedures described by the manufacturer. The RT-qPCR mix consisted of $8 \mu \mathrm{L}$ of SYBR Green Supermix (Bio-Rad Laboratories), $1 \mu \mathrm{L}$ of each primer (0.5 $\mu \mathrm{M}$ final concentration), $5 \mu \mathrm{L}$ of water and $1 \mu \mathrm{L}$ of cDNA. The reaction program consisted of one hold at $95^{\circ} \mathrm{C}$ for $5 \mathrm{~min}$, followed by 40 cycles of $15 \mathrm{~s}$ at $95^{\circ} \mathrm{C}$ and $75 \mathrm{~s}$ at $60^{\circ} \mathrm{C}$. Fragment amplification and detection of SYBR Green (Applied Biosystems, CA, USA) were performed with the Step One Plus thermalcycler (Applied Biosystems). The relative expression ratio was calculated using the $2^{-\triangle \Delta C T}$ method [55] using primers with amplification efficiencies between $90-100 \%(-3.6 \geq$ slope $\geq-3.3)$. The ACT1 and YNL134c genes were selected as endogenous genes to normalize the expression values for the TF and FL samples, respectively, as both genes showed little variation in expression among the different RNA-seq libraries.

\section{Bacterial identification}

Although conventional RNA-seq libraries are enriched for mRNA through the use of oligo(dt) magnetic beads, a small proportion of sequences corresponding to other RNA species is often detected [56], allowing the identification of the bacterial species present in the FL and TF samples. The RNA-seq reads were aligned into the SILVA rRNA database [23] using SOAPaligner, configured to allow two mismatches and discard any repeat reads. A custom Perl script was developed to parse the output file obtaining the read counts per taxon using different taxonomic levels. Bacterial families that accounted for less than $5 \%$ of the total reads from the TF or FL samples were not used in further analyses.

To identify the bacterial species associated with yeast co-aggregation, bacterial colonies were isolated in LB solid medium (tryptone $10 \mathrm{~g} / \mathrm{L}[\mathrm{w} / \mathrm{v}]$, yeast extract $5 \mathrm{~g} / \mathrm{L}$ $[\mathrm{w} / \mathrm{v}], \mathrm{NaCl} 10 \mathrm{~g} / \mathrm{L}[\mathrm{w} / \mathrm{v}]$ and agar $20 \mathrm{~g} / \mathrm{L}[\mathrm{w} / \mathrm{v}])$ under anaerobic conditions. The bacterial DNA extraction protocol was adapted from Collart and Oliviero [50] using lysozyme $(100 \mathrm{mg} / \mathrm{mL})$ and proteinase $\mathrm{K}(10 \mathrm{mg} /$ $\mathrm{mL})$. PCR amplification of the $16 \mathrm{~S}$ rDNA was performed in a final volume of $50 \mu \mathrm{L}$. The reaction mix consisted of $4 \mathrm{ng}$ of DNA, $0.5 \mu \mathrm{M}$ each of F27 (5' AGA GTT TGA TCM TGG CTC AG 3') and R1378 (5' CGG TGT GTA CAA GGC CCG GGA ACG 3') primers [57], $0.25 \mathrm{mM}$ each dNTP, $3.5 \mathrm{mM} \mathrm{MgCl}_{2}$, 1X Colorless GoTaq Flexi Buffer (Promega, Madison, WI, USA) and $1.25 \mathrm{U}$ of GoTaq Flexi DNA Polymerase (Promega). The amplification program consisted of one initial hold at $94^{\circ} \mathrm{C}$ for $3 \mathrm{~min}$, followed by 40 cycles of $30 \mathrm{~s}$ at $94^{\circ} \mathrm{C}$, $30 \mathrm{~s}$ at $55^{\circ} \mathrm{C}$ and $60 \mathrm{~s}$ at $72^{\circ} \mathrm{C}$. A final 5 -min extension was performed at $72^{\circ} \mathrm{C}$. The PCR products were purified using the NucleoSpin Extract II purification kit (Macherey-Nagel, Düren, Germany), according to the manufacturer's instructions. The PCR products (45 ng) were Sanger-sequenced using the Big Dye Terminator kit (Applied Biosystems, Foster City, CA, USA) on a 3500 Genetic Analyzer (Applied Biosystems). The reaction program consisted of one hold at $94^{\circ} \mathrm{C}$ for $2 \mathrm{~min}$, followed by 35 cycles of $20 \mathrm{~s}$ at $94^{\circ} \mathrm{C}, 30 \mathrm{~s}$ at $55^{\circ} \mathrm{C}$ and 2 min at $60^{\circ} \mathrm{C}$. Bacterial rDNA sequence similarity was obtained by BLASTn analysis using the GenBank nonredundant (NR) Database (http://blast.ncbi.nlm.nih.gov/).

\section{RCE1 amplification and genotyping}

For the loss of heterozygosity (LOH) analysis, a segment of the RCE1 gene was PCR-amplified in a final volume reaction of $50 \mu \mathrm{L}$ using $1 \mathrm{ng}$ of yeast genomic DNA, $0.5 \mu \mathrm{M}$ each of RCE1_F (5' ACC TTA TAT TGT GGA CCC GTT 3') and RCE1_R (5' CTC GAT AGA ATT CCA TAA TAG 3') primers, $0.25 \mathrm{mM}$ each dNTP, $3.5 \mathrm{mM} \mathrm{MgCl} 2,1 \mathrm{X}$ Colorless GoTaq Flexi Buffer and $1.25 \mathrm{U}$ of GoTaq Flexi DNA Polymerase (Promega, Madison, WI, USA). The amplification program consisted of one hold at $94^{\circ} \mathrm{C}$ for $2 \mathrm{~min}$, followed by $35 \mathrm{cy}$ cles of $40 \mathrm{~s}$ at $94^{\circ} \mathrm{C}, 40 \mathrm{~s}$ at $56^{\circ} \mathrm{C}$ and $80 \mathrm{~s}$ at $72^{\circ} \mathrm{C}$. A final 5-min extension was performed at $72^{\circ} \mathrm{C}$. The PCR products were purified and digested using $10 \mathrm{U}$ of $\mathrm{MboI}$ (New England Biolabs, Ipswich, MA, USA). The digested fragments were resolved in $2 \%(\mathrm{w} / \mathrm{v})$ agarose gels and visualized by ethidium bromide staining.

\section{Additional files}

Additional file 1: Table S1. Reads obtained by RNA-seq analysis during
industrial bioethanol production. For each RNA-seq library, reads were
aligned to a custom reference gene database constituted by S. cerevisiae
S288c genes (wwW.yeastgenome.org) and 20 JAY291-specific genes. In
order to assigned ribosomal sequences, reads were aligned into the
SILVA rRNA database.
Additional file 2: Table S2. Differentially expressed genes among the
fermentations. Pairwise comparisons between fermentation conditions
(typical versus flocculated) were performed using the time points within
fermentation (TF1-TF6 and FL1-FL7) as experimental replicates. A p-value
cutoff of 0.01, with a fold change > 2 (up-regulated) or <-2 (down-
regulated), were used to determine the differentially expressed (DE)
genes in this comparison. Gene expression levels were defined using
the RPKM formula.

Additional file 1: Table S1. Reads obtained by RNA-seq analysis during aligned to a S288C genes (www.yeastgenome.org) and 20 JAY291-specific genes. In order to assigned ribosomal sequences, reads were aligned into the SILVA rRNA database.

Additional file 2: Table S2. Differentially expressed genes among the

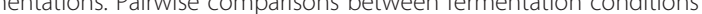
fermentation (TF1-TF6 and FL1-FL7) as experimenta replicates. A p-value cutoff of 0.01 , with a fold change $>2$ (up-regulated) or $<-2$ (downgenes in this the RPKM formula. 
Additional file 3: Table S3. Differentially expressed genes during flocculated fermentation. Pairwise comparisons within flocculated fermentation time points were performed using FL1 sample as reference. A p-value cutoff of 0.01 , with a fold change $>2$ (up-regulated) or $<-2$ (down-regulated), were used to determine the differentially expressed (DE) genes in these comparisons. Gene expression levels were defined using the RPKM formula.

Additional file 4: Table S4. Differentially expressed genes during typical fermentation. Pairwise comparisons within typical fermentation time points were performed using TF1 sample as reference. A p-value cutoff of 0.01 , with a fold change $>2$ (up-regulated) or $<-2$ (downregulated), were used to determine the differentially expressed (DE) genes in these comparisons. Gene expression levels were defined using the RPKM formula.

Additional file 5: Figure S1. Correlation between RNA-seq and rt-qPCR data to fifteen selected genes. A- Flocculated fermentation (FL); B- Typical fermentation (TF). Samples TF1 and FL1 were used as references in order to obtain expression ratio among TF4 and TF6 and FL4 and FL7 samples, respectively. Expression values were obtained using three techniques replicates and are presented as fold change Log2.

Additional file 6: Table S5. Enriched GO terms between fermentations. Gene ontology $(\mathrm{GO})$ terms of the differentially expressed $(\mathrm{DE})$ genes were obtained from SGD (http://www.yeastgenome.org/cgi-bin/GO/ goSlimMapper.pl) using the Yeast GO-Slim Process parameters and a cutoff $p$-value $<0.01$. Functional $G O$ enrichment terms were obtained using DE genes between fermentations (TF1 vs. FL1; TF6 vs. FL7; TFs vs. FLs). FL: Flocculated fermentation. TF: Typical fermentation.

Additional file 7: Table S6. Genes with differential allelic expression. Differential allelic expression (DAE) was determined using a threshold of 2 -fold between alleles, i.e., more than $66 \%$ of the reads aligned to a specific gene came from a single allele. When the coding region had more than one heterozygous SNP, DAE was determined accounting for the cumulative imbalance for all the phased SNPs across the entire gene. DAE was identified in both fermentations (TF and FL), exclusively in TF and exclusively in FL. FL: Flocculated fermentation. TF: Typical fermentation.

Additional file 8: Table S7. List of genes, PCR products, and primers used in rt-qPCR analysis.

\section{Abbreviations}

Chr: Chromosome; DAE: Differential allelic expression; DE: Differential expression; GSH: Glutathione; Kb: Kilobase pairs; LOH: Loss of heterozygosity; MET: Methionine; RT-qPCR: Reverse transcriptase quantitative polymerase chain reaction; SNP: Single nucleotide polymorphism.

\section{Competing interests}

The authors report no conflicts of interest.

\section{Author contributions}

OVCN performed the experiments and analyzed the data; MFC, LSM and MFN performed the bioinformatics analysis; PJPLT and PAM prepared the RNA-seq libraries and performed the sequencing; LALC performed the kinetics analyses; JLA performed the allelic differential expression analysis; OVCN and GAGP designed the experimental approach. OVCN, MFC, PJPLT, JLA and GAGP wrote the manuscript. All authors read and approved the final manuscript.

\section{Acknowledgments}

We would like to thank Usina Nova América (Maracaí-SP) for providing biological materials, and Center for Computational Engineering and Sciences - FAPESP/Cepid (2013/08293-7). This work was supported by Odebrecht Agroindustrial S/A, FAPESP (2008/51500-5) and CNPq. Bioenergy research in the Argueso laboratory was supported in part by a seed grant from the Colorado State University Clean Energy Supercluster.

\section{Author details}

'Departamento de Genética, Evolução e Bioagentes, Instituto de Biologia, Universidade Estadual de Campinas, Campinas, SP, Brazil. ${ }^{2}$ Department of Environmental and Radiological Health Sciences, Colorado State University,
Fort Collins, CO, USA. ${ }^{3}$ Department of Genetics, University of North Carolina, Chapel Hill, NC, USA.

Received: 13 September 2014 Accepted: 13 January 2015 Published online: 30 January 2015

\section{References}

1. Basso LC, de Amorim HV, de Oliveira AJ, Lopes ML. Yeast selection for fuel ethanol production in Brazil. FEMS Yeast Res. 2008;8:1155-63.

2. Carvalho-Netto OV, Carazzolle MF, Rodrigues A, Bragança WO, Costa GGL, Argueso $J$, et al. A simple and effective set of PCR-based molecular markers for the monitoring of the Saccharomyces cerevisiae cell population during bioethanol fermentation. J Biotechnol. 2013;168:701-9.

3. Da Silva-Filho EA, Santos SK B d, Resende ADM, de Morais JOF, de Morais MA, Ardaillon Simões D. Yeast population dynamics of industrial fuel-ethanol fermentation process assessed by PCR-fingerprinting. Antonie Van Leeuwenhoek. 2005:88:13--23.

4. Argueso JL, Carazzolle MF, Mieczkowski PA, Duarte FM, Carvalho-Netto OV, Missawa SK, et al. Genome structure of a Saccharomyces cerevisiae strain widely used in bioethanol production. Genome Res. 2009;19:2258-70.

5. Soares EV. Flocculation in Saccharomyces cerevisiae: a review. J Appl Microbiol. 2011;110:1-18.

6. Verstrepen $\mathrm{KJ}$, Klis FM. Flocculation, adhesion and biofilm formation in yeasts. Mol Microbiol. 2006;60:5-15.

7. Amorim HV, Lopes ML, de Castro Oliveira JV, Buckeridge MS, Goldman GH. Scientific challenges of bioethanol production in Brazil. Appl Microbiol Biotechnol. 2011;91:1267-75.

8. Abreu-Cavalheiro A, Monteiro G. Solving ethanol production problems with genetically modified yeast strains. Braz J Microbiol. 2014;44(3):665-71.

9. Lucena BTL, dos Santos BM, Moreira JL, Moreira APB, Nunes AC, Azevedo V, et al. Diversity of lactic acid bacteria of the bioethanol process. BMC Microbiol. 2010;10:298.

10. Yokoya F, Oliva-Neto P. Características da floculação de leveduras por Lactobacillus fermentum. Brazilian J Microbiol. 1991;22:12-6.

11. Tiukova I, Eberhard T, Passoth V. Interaction of Lactobacillus vini with the ethanol-producing yeasts Dekkera bruxellensis and Saccharomyces cerevisiae. Biotechnol Appl Biochem. 2014;61:40-4.

12. Pretzer G, Snel J, Molenaar D. Biodiversity-based identification and functional characterization of the mannose-specific adhesin of Lactobacillus plantarum. J Bacteriol. 2005;187:6128-36.

13. Furukawa S, Nojima N, Nozaka S, Hirayama S, Satoh A, Ogihara H, et al. Mutants of Lactobacillus plantarum ML11-11 deficient in co-aggregation with yeast exhibited reduced activities of mixed-species biofilm formation. Biosci Biotechnol Biochem. 2012;76:326-30.

14. Turner MS, Hafner LM, Walsh T, Giffard PM. Peptide surface display and secretion using two LPXTG-containing surface proteins from Lactobacillus fermentum BR11. Appl Environ Microbiol. 2003;69:5855-63.

15. Hirayama S, Furukawa S, Ogihara H, Morinaga Y. Yeast mannan structure necessary for co-aggregation with Lactobacillus plantarum ML11-11. Biochem Biophys Res Commun. 2012;419:652-5.

16. Rayner JC, Munro S. Identification of the MNN2 and MNN5 mannosyltransferases required for forming and extending the mannose branches of the outer chain mannans of Saccharomyces cerevisiae. J Biol Chem. 1998:273:26836-43.

17. Abbott DA, Zelle RM, Pronk JT, van Maris AJA. Metabolic engineering of Saccharomyces cerevisiae for production of carboxylic acids: current status and challenges. FEMS Yeast Res. 2009;9:1123-36.

18. Dorta C, Oliva-Neto P, Abreu-Neto MS, Nicolau-Junior N, Nagashima Al. Synergism among lactic acid, sulfite, $\mathrm{pH}$ and ethanol in alcoholic fermentation of Saccharomyces cerevisiae (PE-2 and M-26). World J Microbiol Biotechnol. 2005;22:177-82.

19. Kawahata M, Masaki K, Fujii T, lefuji $\mathrm{H}$. Yeast genes involved in response to lactic acid and acetic acid: acidic conditions caused by the organic acids in Saccharomyces cerevisiae cultures induce expression of intracellular metal metabolism genes regulated by Aft1p. FEMS Yeast Res. 2006;6:924-36.

20. Thomas KC, Hynes SH, Ingledew WM. Influence of medium buffering capacity on inhibition of Saccharomyces cerevisiae growth by acetic and lactic acids. Appl Environ Microbiol. 2002;68:1616-23.

21. Narendranath NV, Thomas KC, Ingledew WM. Effects of acetic acid and lactic acid on the growth of Saccharomyces cerevisiae in a minimal medium. $\mathrm{J}$ Ind Microbiol Biotechnol. 2001;26:171-7. 
22. Argueso JL, Pereira GAG. Perspective: Indigenous sugarcane yeast strains as ideal biological platforms for the delivery of next generation biorefining technologies. Int Sugar J. 2010;112:86-9.

23. Pruesse E, Quast C, Knittel K, Fuchs BM, Ludwig W, Peplies J, et al. SILVA: a comprehensive online resource for quality checked and aligned ribosomal RNA sequence data compatible with ARB. Nucleic Acids Res. 2007;35:7188-96.

24. Bakker BM, Overkamp KM, van Maris AJ, Kötter P, Luttik MA, van Dijken JP, et al. Stoichiometry and compartmentation of NADH metabolism in Saccharomyces cerevisiae. FEMS Microbiol Rev. 2001;25:15-37.

25. Nevoigt E, Stahl U. Osmoregulation and glycerol metabolism in the yeast Saccharomyces cerevisiae. FEMS Microbiol Rev. 1997;21:231-41.

26. Ishida N, Saitoh S, Ohnishi T, Tokuhiro K, Nagamori E, Kitamoto K, et al. Metabolic engineering of Saccharomyces cerevisiae for efficient production of pure L-(+)-lactic acid. Appl Biochem Biotechnol. 2006;131:795-807.

27. Oliva-Neto P, Yokoya F. Evaluation of bacterial contamination in a fed-batch alcoholic fermentation process. World J Microbiol Biotechnol. 1994;10:697-9.

28. Geng F, Laurent BC. Roles of SWI/SNF and HATs throughout the dynamic transcription of a yeast glucose-repressible gene. EMBO J. 2004;23:127-37.

29. Ozcan S, Vallier LG, Flick JS, Carlson M, Johnston M. Expression of the SUC2 gene of Saccharomyces cerevisiae is induced by low levels of glucose. Yeast. 1997;13:127-37.

30. Basso LC, Basso TO, Rocha SN. Ethanol production in Brazil : the industrial process and its impact on yeast fermentation. In: Bernardes MAS, editor. Biofuel Production - Recent Developments and Prospects. Volume 1. Rijeka: InTech; 2010. p. 85-100.

31. Piper P, Ortiz Calderon C, Hatzixanthis K, Mollapour M. Weak acid adaptation; the stress response that confers yeasts with resistance to organic acid food preservatives. Microbiology. 2001;147:2635-42.

32. Serrano R, Kielland-Brandt MC, Fink GR. Yeast plasma membrane ATPase is essential for growth and has homology with $(\mathrm{Na}++\mathrm{K}+), \mathrm{K}+-$ and $\mathrm{Ca} 2$ +-ATPases. Nature. 1986:319:689-93.

33. Abbott DA, Knijnenburg TA, Poorter LMI, Reinders MJT, Pronk JT, van Maris AJ. Generic and specific transcriptional responses to different weak organic acids in anaerobic chemostat cultures of Saccharomyces cerevisiae. FEMS Yeast Res. 2007:7:819-33.

34. Abbott DA, Suir E, van Maris AJA, Pronk JT. Physiological and transcriptional responses to high concentrations of lactic acid in anaerobic chemostat cultures of Saccharomyces cerevisiae. Appl Environ Microbiol. 2008;74:5759-68.

35. Fernandes AR, Mira NP, Vargas RC, Canelhas I, Sá-Correia I. Saccharomyces cerevisiae adaptation to weak acids involves the transcription factor Haa1p and Haa1p-regulated genes. Biochem Biophys Res Commun. 2005;337:95-103.

36. Mira NP, Becker JD, Sá-Correia I. Genomic expression program involving the Haa1p-regulon in Saccharomyces cerevisiae response to acetic acid. OMICS. 2010;14:587-601.

37. Mira NP, Palma M, Guerreiro JF, Sá-Correia I. Genome-wide identification of Saccharomyces cerevisiae genes required for tolerance to acetic acid. Microb Cell Fact. 2010;9:79.

38. Grant CM, Maclver FH, Dawes IW. Glutathione is an essential metabolite required for resistance to oxidative stress in the yeast Saccharomyces cerevisiae. Curr Genet. 1996;29:511-5.

39. Stephen DW, Jamieson DJ. Glutathione is an important antioxidant molecule in the yeast Saccharomyces cerevisiae. FEMS Microbiol Lett. 1996;141:207-12.

40. Grant CM. Role of the glutathione/glutaredoxin and thioredoxin systems in yeast growth and response to stress conditions. Mol Microbiol. 2001;39:533-41.

41. Wheeler GL, Trotter EW, Dawes IW, Grant CM. Coupling of the transcriptional regulation of glutathione biosynthesis to the availability of glutathione and methionine via the Met4 and Yap1 transcription factors. J Biol Chem. 2003;278:49920-8.

42. Dormer UH, Westwater J, McLaren NF, Kent NA, Mellor J, Jamieson DJ. Cadmium-inducible expression of the yeast GSH1 gene requires a functional sulfur-amino acid regulatory network. J Biol Chem. 2000;275:32611-6.

43. Abbott DA, Suir E, Duong G-H, De Hulster E, Pronk JT, van Maris AJ. Catalase overexpression reduces lactic acid-induced oxidative stress in Saccharomyces cerevisiae. Appl Environ Microbiol. 2009;75:2320-5.

44. Ludovico P, Rodrigues F, Almeida A, Silva MT, Barrientos A, Côrte-Real M. Cytochrome $c$ release and mitochondria involvement in programmed cell death induced by acetic acid in Saccharomyces cerevisiae. Mol Biol Cell. 2002;13:2598-606.
45. Rodríguez-Navarro S, Llorente B, Rodríguez-Manzaneque MT, Ramne A, Uber $G$, Marchesan D, et al. Functional analysis of yeast gene families involved in metabolism of vitamins B1 and B6. Yeast. 2002;19:1261-76.

46. Padilla PA, Fuge EK, Crawford ME, Errett A, Werner-Washburne M. The highly conserved, coregulated SNO and SNZ gene families in Saccharomyces cerevisiae respond to nutrient limitation. J Bacteriol. 1998;180:5718-26.

47. Ehrenshaft M, Bilski P, Li MY, Chignell CF, Daub ME. A highly conserved sequence is a novel gene involved in de novo vitamin B6 biosynthesis. Proc Natl Acad Sci U S A. 1999;96:9374-8.

48. Stambuk BU, Dunn B, Alves SL, Duval EH, Sherlock G. Industrial fuel ethanol yeasts contain adaptive copy number changes in genes involved in vitamin B1 and B6 biosynthesis. Genome Res. 2009;19:2271-8.

49. Hoffman CS. Preparation of yeast DNA. In: Ausubel FM, Brent R, Kingston RE, Moore DD, Seidman JG, Smith JA, Struhl K, editors. Current Protocols in Molecular Biology. New York: John Wiley \& Sons; 2001. p. 13-1.

50. Collart MA, Oliviero S. Preparation of Yeast RNA. In: Ausubel FM, Brent R, Kingston RE, Moore DD, Seidman JG, Smith JA, Struhl K, editors. Current Protocols in Molecular Biology. New York: John Wiley \& Sons; 2001. p. 13-2.

51. Li R, Li Y, Kristiansen K, Wang J. SOAP: short oligonucleotide alignment program. Bioinformatics. 2008;24:713-4.

52. Wang L, Feng Z, Wang $X$, Wang $X$, Zhang $X$. DEGseq: an $R$ package for identifying differentially expressed genes from RNA-seq data. Bioinformatics. 2010;26:136-8

53. Mortazavi A, Williams BA, Mccue K, Schaeffer L, Wold B. Mapping and quantifying mammalian transcriptomes by RNA-Seq. Nat Methods. 2008:5:1-8.

54. Sharan R, Maron-Katz A, Shamir R. CLICK and EXPANDER: a system for clustering and visualizing gene expression data. Bioinformatics. 2003;19:1787-99.

55. Livak KJ, Schmittgen TD. Analysis of relative gene expression data using real-time quantitative PCR and the 2(-Delta Delta C(T)) method. Methods. 2001;25:402-8

56. Cui $P$, Lin $Q$, Ding F, Xin C, Gong W, Zhang $L$, et al. A comparison between ribo-minus RNA-sequencing and polyA-selected RNA-sequencing. Genomics. 2010;96:259-65.

57. Heuer H, Krsek M, Baker P, Smalla K, Wellington EM. Analysis of actinomycete communities by specific amplification of genes encoding $16 \mathrm{~S}$ rRNA and gel-electrophoretic separation in denaturing gradients. Appl Environ Microbiol. 1997;63:3233-41.

\section{Submit your next manuscript to BioMed Central and take full advantage of:}

- Convenient online submission

- Thorough peer review

- No space constraints or color figure charges

- Immediate publication on acceptance

- Inclusion in PubMed, CAS, Scopus and Google Scholar

- Research which is freely available for redistribution

Submit your manuscript at www.biomedcentral.com/submit
C Biomed Central 